\title{
Digital Weather Stations as a Part of Wind Power Station
}

\author{
Fawzy M. Al Zureiqat, Yasir Khalil Al Hussein \\ Department of Communications and Electronics Engineering, College of Engineering, Jerash University, Jerash, Jordan \\ Email: dr_fawzy2010@hotmail.com,dr.yasir.khalil@gmail.com
}

How to cite this paper: Al Zureiqat, F.M. and Al Hussein, Y.K. (2017) Digital Weather Stations as a Part of Wind Power Station. Journal of Signal and Information Processing, 8, 9-16.

https://doi.org/10.4236/jsip.2017.81002

Received: December 11, 2016

Accepted: January 16, 2017

Published: January 19, 2017

Copyright $\odot 2017$ by authors and Scientific Research Publishing Inc. This work is licensed under the Creative Commons Attribution International License (CC BY 4.0).

http://creativecommons.org/licenses/by/4.0/

(c) (i) Open Access

\begin{abstract}
This paper mainly studies Weather Stations part of the wind power station. The use of wind energy in practice is carried out using the facilities of the wind in which the kinetic energy of the windscreen flow is converted into mechanical energy wind speed, then electrical energy alternator. The effective operation of the wind turbine is dependent on the direction of the wind. Speed air density, which in turn depends on the temperature and humidity. Thus, the speed of the wind worked effectively in its composition must include the weather. Meteorological station also performs the role of prevention. When the sharp wind speed or increase wind speed above the maximum value, it sends a signal to the lock assembly wind to prevent wind turbine technology from damage. The work of the meteorological stations design as part of the Wind Energy Station is considered. The complex technical devices are used for its implementation. A set of technical means used to its implementation and designed system consists of a temperature, humidity, wind speed, wind direction and rain gauge sensors that are connected to PIC16f876A microcontroller.
\end{abstract}

\section{Keywords}

Digital Weather Station, Effectively Monitor, Wind Speed, PIC16f876A, Power Station

\section{Introduction}

Weather is the state of the atmosphere, to the degree that it is hot or cold, wet or dry, calm or stormy, clear or cloudy. Weather, seen from an anthropological perspective, is something all humans in the world constantly experience through their senses, at least while being outside. There are socially and scientifically constructed understandings of what weather is, what makes it change, what effects it has on humans in different situations etc. Therefore, weather is something people often communicate about. Turning back to the meteorological 
perspective, most weather phenomena occur in the troposphere, just below the stratosphere. Weather generally refers to day-to-day temperature and precipitation activity, whereas climate is the term for the average atmospheric conditions over longer periods of time. When used without qualification, "weather", is generally understood to mean the weather of Earth. Weather occurs due to density (temperature and moisture) differences from one place to another. These differences can occur due to the sun angle at any particular spot, which varies by latitude from the tropics. The strong temperature contrast between polar and tropical air gives rise to the jet stream. Weather systems in the mid-latitudes, such as extra tropical cyclones, are caused by instabilities of the jet stream flow. Because the Earth's axis is tilted relative to its orbital plane, sunlight is incident at different angles at different times of the year. On Earth's surface, temperatures usually range $\pm 40^{\circ} \mathrm{C}\left(-40^{\circ} \mathrm{F}\right.$ to $\left.104^{\circ} \mathrm{F}\right)$ annually. Over thousands to hundreds of thousands of years, changes in Earth's orbit affect the amount and distribution of solar energy received by the Earth and influence long-term climate [1].

Surface temperature differences in turn cause pressure differences. Higher altitudes are cooler than lower altitudes due to differences in compression heating. Weather forecasting is the application of science and technology to predict the state of the atmosphere for a future time and a given location. The atmosphere is a chaotic system, so small changes to one part of the system can grow to have large effects on the system as a whole. Human attempts to control the weather have occurred throughout human history, and there is evidence that human activity such as agriculture and industry has inadvertently modified weather patterns [2]. Sensors are essential components in many applications, not only in the industries for process control but also in daily life for buildings safety and security monitoring, traffic flow measuring, weather condition monitoring and etc. In weather monitoring, for instance, parameters such as temperature, humidity and pressure need to be measured, thus sensors have always been given the task for doing so. Weather or climate plays an important role in human life. The thermal comfort of human being is known to be influenced mostly by six parameters, i.e., air temperature, radiation, air flow, humidity, activity level and clothing thermal resistance. The advancement in technology has made these small and reliable electronic sensors capable of monitoring environmental parameters more favorably [3].

\section{Wind Characteristic}

The effective operation of the wind turbine is dependent on the direction of the Wind Speed, air density, which in turn depends on the temperature and humidity in such a way as to wind worked Effectively in its composition must include weather. Weather station also performs a warning role. When the sharp speed of wind or increasing the wind speed above the maximum value it sends a signal to the lock during exit from the wind turbine technology failure.

There are analog and digital weather On the Classic (analog) Weather there is: 
- Thermometer for measuring temperature;

- Barometer for measuring the pressure;

- Hygrometer to measure the moisture of the air;

- Anemometer for the wind speed measurement;

Wind the inventory is the sum of the characteristics of the wind to identify its energy value and to identify possible modes of wind installations.

Basic inventory the characteristics of the Wind

1) The average wind speed;

2) Annual and daily run wind; Repeatability wind speeds;

3) Repeatability of wind and distribution of wind periods and periods of duration;

4) Maximum wind speed and Specific power and specific wind energy;

The Wind resources of the area weather generally refer to day-to-day temperature and precipitation activity, whereas climate is the term for the average atmospheric conditions over longer periods of time. When used without qualification [4]. Weather station should be able to identify all the necessary for the work of the Wind Farm installation specifications: Wind speed, annual and daily the wind, repeatability wind speeds, repeatability of the wind, the distribution of the Wind periods and periods of duration, the maximum speed, wind power density and specific gravity wind energy. This system will be a powerful and flexible tool that will offer this service at any time, and from anywhere with the constraints of the technologies being applied.

\section{Wind Data Processing and Design}

The proposed approach for designing this system is to implement a PIC microcontroller based control module that reads weather parameters from sensors and receives its instructions and commands from a cellular phone over the GSM network. The microcontroller then would send the measured weather parameters to the users over the GSM network, designed system block diagram shown in Figure 1.

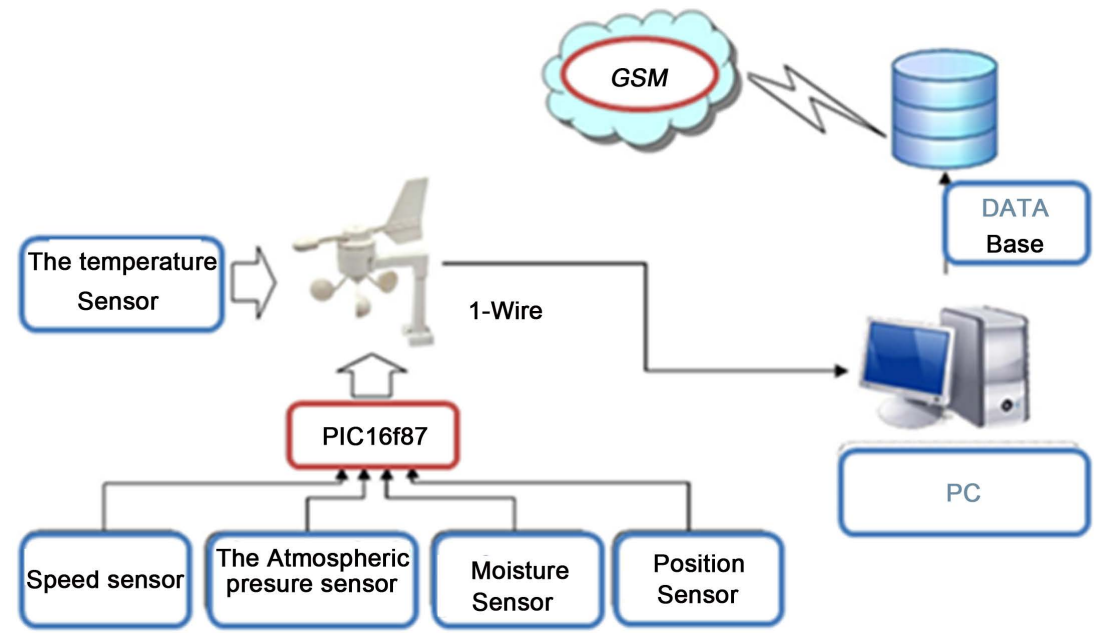

Figure 1. Designed system block diagram. 
Using easily-available components and simple circuitry, the system should be beneficial in providing a portable and low-cost remote weather monitoring system. The basis of the weather station was elected a single 1-Wire interface, this interface is controlled by the developers for use in four major areas of application: devices in special enclosures Microcap to solve problems of identification, migration or conversion information I Button technology [4].

\section{Automation Systems Technology 1-Wire-Networks-Networks}

Wire devices are a powerful, yet very cost-effective way to add electronic functionality to non-electronic objects for identification, authentication, and delivery of calibration data or manufacturing information. Contrary to the name, a 1Wire device actually uses 2-wires-data and ground, for half-duplex bidirectional communication. It is a serial protocol designed by Dallas Semiconductor Corp., which provides low-speed data, signaling, and power over a single signal. The 1-Wire master controls the communications with one or more slave devices. Each of them has a unique 64-bit ID on the 1-Wire bus. Its subset, an 8-bit family code identifies the device type and functionality.

There are two types of 1 - Wire devices.

- Single component or one of many components in integrated circuit and TO92 packaging.

- I Button, a portable device that looks like a watch battery. It is used in alarm system, in computer and many other things for user authentication.

Wire-net is an information network that uses to implement digital communication line data and one breakout (Earth) wire. Thus, to implement the network Exchange Wednesday can be applied for available cables that contain unshielded twisted pair category, and even an ordinary phone wire. Such cables when laying them do not require any special equipment; limitation of the maximum length of a single developers up to $300 \mathrm{~m}$. Foundation of 1-Wire networks is a shared bus topology, where each is connected directly to a single line, without branches When this is used as the basic network structure leading or master PC or microcontroller led devices temperature sensors, ADC, etc. [5]. Speed limit in exchange network is $16.3 \mathrm{Kbit} / \mathrm{s}$ and is more for use in the field of automation

Particularly attractive quality 1-Wire-technology is an exceptional ease of customization, debugging and maintenance of networks of virtually any configuration, built to this standard. Indeed, enough to get started any personal computer, an inexpensive adapter 1-Wire-lines, as well as one of the freely distributed company Dallas Semiconductor test programs: either I Button Viewer shell, or a developer package the One Wire Viewer. With this small number of constituent organization functioning 1-Wire networks of any complexity based on standard wire components, implemented literally within minutes. Opportunities offered by the I Button Viewer and One Wire Viewer programs allow with maximum comfort for the developer to identify any guest wire devices on the 1Wire line and check that it is correctly in full operation composed of configura- 
ble 1-Wire network. In accordance with the structural schema in the composition of the weather station includes the following components:-temperatureanalog-to-digital converter,-wind speed sensor-sensor wind direction is absolute pressure sensor [6].

The Measurement range from $-55^{\circ} \mathrm{C}$ to $125^{\circ} \mathrm{C}$ accuracy $0.5^{\circ} \mathrm{C}$ in the range$85^{\circ} \mathrm{C}$ minus 10 in addition DS1820 can be powered with voltage line data (parasite power) in the absence of an external voltage source. Digital code read thermometer is a direct result of the measured temperature values in additional conversion to service analog sensor

The manifold pressure sensor and moisture sensor) applied quad-channel 16-bit ADC TYPE DS2450. It represents a converter analog signal into digital works in a sequential mode approach, with an analog port are provided 4 to 1. Each channel has its own register, which set and stored input voltage range, the resolution and the value of the warning thresholds used for the installation of warning check boxes. If the input voltage is outside the specified range, the check boxes to allow the participation of the tool in the conditional search. For each channel are the two warning box [7].

Without the requirement to drive tires simply indicate whether the measured voltage is above or below specified thresholds. Each transform ADC is initialized leading bus. The range of the measured voltages can be set programmatically from 0 to 2.56 in either from 0 to $5.12 \mathrm{~V}$.

Moisture measuring is analog moisture sensor Honeywell earthquake. It is designed to measure the relative air humidity from $0 \%$ to $100 \%$. The basis of Sensors-the sensing element that represents a-fabric, constituted by two flat platinum theme that provides and dielectric polymer, filling the space between them. resin, compared with a thermosetting plastics, provides the sensor over a wide range of operating temperatures and high chemical resistance to such aggressive liquids and couples in the process of the work of the water steam penetrates through the upper porous around the condenser and is balanced with the surrounding gas. At the same time this liner protects the electrical processes, leaking in the polymer layer from the external physical effects (light and electromagnetic radiation). The layer of resin that covers the porous platinum electrode to the top is the protection of the con-denser from dust, dirt and oils. This powerful filtration system, on the one hand, provides the sensor long uninterrupted work in conditions of strong contamination of the environment on the other-reduces response time.

For the wind speed measurement applied optical Incremental Encoder. Optical encoder is strictly docked on the shaft drive with optical grid and stationary unit-measuring head that includes a light source. When the shaft is turning the grid moves to the stationary measuring head, the modulated light flow, This type of encoded according, unlike the absolute does not generate the output pulses when the shaft is located in the quiet. Thus obtained pulses with frequency, the speed of rotation of the shaft, arrive at the entrance of the frequency converter in voltage. To convert frequency to the voltage applied integrated chip type LM2917 with linear dependence of the output voltage from the input. 
Frequency of the signal is sent to one of the inputs of the ADC. This implementation for the wind speed measurement enabled shows all components are gathered to form the complete The PIC microcontroller is the main block, it acts as the brain of the system because it will get the data from the sensors and process it then output the data in the appropriate format to the user's mobile in a message SMS via the GSM modem. The PIC will receive the user's SMS via the GSM modem, and then read the 5 sensors outputs and send it back to the user in SMS via the GSM modem [8].

\section{System Flowchart}

The system starts with the inputs and outputs initializations then read the sensors outputs; it reads the temperature, the humidity, the wind speed, rain gauge and wind direction sensors' outputs values. Then if an SMS is received, the system will reply the sender with an SMS included the devices' outputs values shown in Figure 2.

\section{Mikro Basic Software}

PRO MikroBasic for PIC is a full-featured basic compiler, which makes a Microchip PIC ${ }^{\circledast}$ development suitable for all. The popular Basic programming language is the best choice for beginners on the simple syntax and reset code. A good IDE with comprehensive background file and free lifetime technical support means a lot when users make the first steps in the world PIC microcontrollers. Not to mention the more than 500 ready-to-use library functions and examples will help the user's development [7].

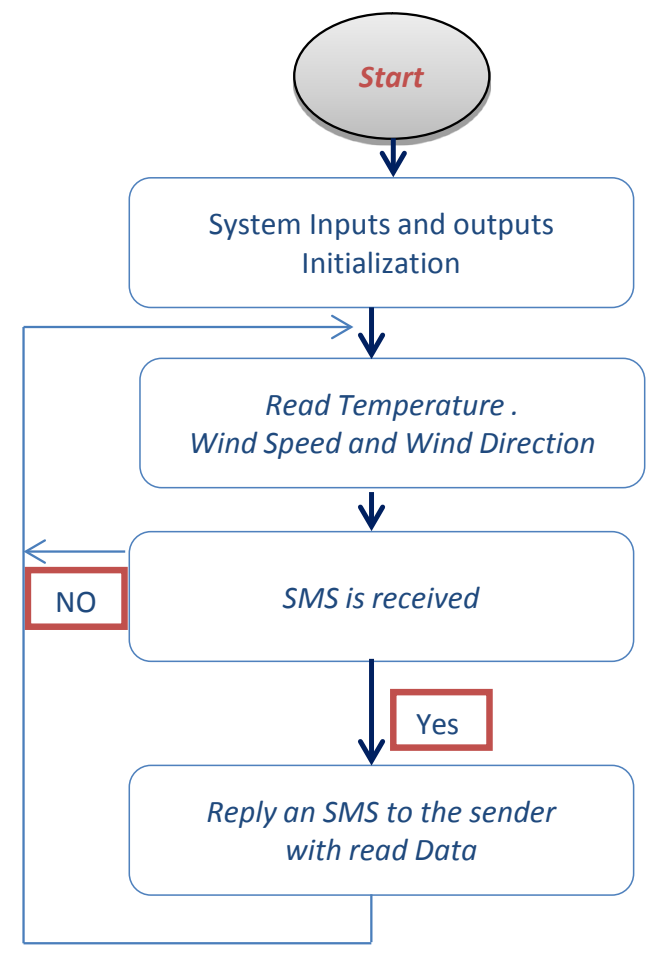

Figure 2. System architecture. 


\section{PIC Programming Process}

A single mouse click on the appropriate icon in the compiler results in the creation of a new document with the extension. The hex it is actually the same program, only the consolidated in machine language that the Microcontroller is well aware. Such programs are usually called the hexadecimal code and forms seemed to be the meaning of the sequence of the hexadecimal numbers.

When the program must be loaded into the chip for hexadecimal code must be loaded into the microcontroller must provide special device under the name of the program, with the relevant software. A large number of programs and electronic circuits used for this purpose can be found on the Internet. The procedure is basically the same for all of them and looks as follows.

- Install the controller in the appropriate program on the mains.

- Use the appropriate cable to connect the program to the PC.

- Open the hexadecimal code of the document in the Program software, install multiple settings and click on the icon for the transfer of the Code. After a few seconds, the sequence of zeros and ones will be entered in the microcontroller. And all that left-to set the program chip in the target device [8] [9] shown in Figure 3.

The diagram of the system starts with the inputs and outputs of the initializations then read the sensors outputs; it reads the temperature, humidity, wind speed and rain gauge and the direction of the Wind Sensors outputs values. Then if the SMS received, the system will respond to the sender using SMS includes the device' outputs values [10].

\section{Conclusion}

Weather station was designed as a component of the Wind Farm installation, and thanks to the use of the 1-wire technology, can be applied for both the consumer and industrial destination. Weather station captures all the features and indicators required for the wind. The low cost and high accuracy of the weather, as well as connecting additional sensors can significantly expand the area of its application. It can be used for various purposes such as weather forecasting, determine the characteristics of the road, Brodsky, etc. Join in one network of a

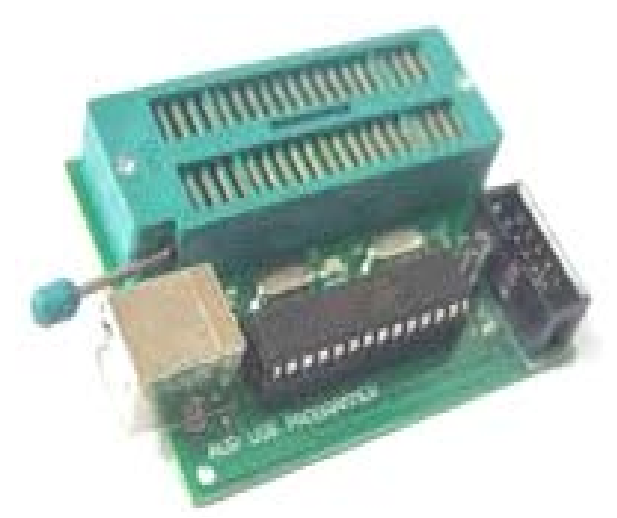

Figure 3. PIC programmer. 
large number of such websites, as well as the accumulated data base will allow a more detailed study of meteorological data and to carry out a more accurate forecasting. The system is cost effective due to using the PIC microcontroller and some components are hand-manufactured. This enhanced our knowledge in testing the components and dealing with it.

\section{Acknowledgements}

This work was supported by the Deanship of Scientific Research, Jerash University.

\section{References}

[1] Muller, C.L., Chapman, L., Johnston, S., Kidd, C., Illingworth, S., Foody, G., Leigh, R.R., et al. (2015) Crowdsourcing for Climate and Atmospheric Sciences: Current Status and Future Potential. International Journal of Climatology, 35, 3185-3203. https://doi.org/10.1002/joc.4210

[2] Al Smadi, T.A. (2013) Design and Implementation of Double Base Integer Encoder of Term Metrical to Direct Binary. Journal of Signal and Information Processing, 4, 370. https://doi.org/10.4236/jsip.2013.44047

[3] Cassola, F. and Burlando, M. (2012) Wind Speed and Wind Energy Forecast through Kalman Filtering of Numerical Weather Prediction Model Output. Applied Energy, 99, 154-166. https://doi.org/10.1016/j.apenergy.2012.03.054

[4] Budischak, C., Sewell, D., Thomson, H., Mach, L., Veron, D.E. and Kempton, W. (2013) Cost-Minimized Combinations of Wind Power, Solar Power and Electrochemical Storage, Powering the Grid up to $99.9 \%$ of the Time. Journal of Power Sources, 225, 60-74. https://doi.org/10.1016/j.jpowsour.2012.09.054

[5] Sliz-Szkliniarz, B. and Vogt, J. (2011) GIS-Based Approach for the Evaluation of Wind Energy Potential: A Case Study for the Kujawsko-Pomorskie Voivodeship. Renewable and Sustainable Energy Reviews, 15, 1696-1707. https://doi.org/10.1016/j.rser.2010.11.045

[6] Ali, H., Qawaqzeh, M.Z., Abbas, M. and Al Smadi, T. (2015) Implementation \& Comparative Analysis of 10, 18 \& 24 Level Diode Clamped Inverters Using “Trust Region Dog Leg" Method. Circuits and Systems, 6, 70. https://doi.org/10.4236/cs.2015.63008

[7] Nema, P., Nema, R.K. and Rangnekar, S. (2009) A Current and Future State of Art Development of Hybrid Energy System Using Wind and PV-Solar: A Review. Renewable and Sustainable Energy Reviews, 13, 2096-2103.

[8] Benghanem, M. (2010) RETRACTED: A Low Cost Wireless Data Acquisition System for Weather Station Monitoring. Renewable Energy, 35, 862-872. https://doi.org/10.1016/j.renene.2009.08.024

[9] Addink, J. and Givargis, T. (2004) U.S. Patent No. 6714134. U.S. Patent and Trademark Office, Washington DC.

[10] Schuol, J. and Abbaspour, K.C. (2007) Using Monthly Weather Statistics to Generate Daily Data in a SWAT Model Application to West Africa. Ecological Modelling, 201, 301-311. https://doi.org/10.1016/j.ecolmodel.2006.09.028 
Submit or recommend next manuscript to SCIRP and we will provide best service for you:

Accepting pre-submission inquiries through Email, Facebook, LinkedIn, Twitter, etc. A wide selection of journals (inclusive of 9 subjects, more than 200 journals)

Providing 24-hour high-quality service

User-friendly online submission system

Fair and swift peer-review system

Efficient typesetting and proofreading procedure

Display of the result of downloads and visits, as well as the number of cited articles Maximum dissemination of your research work

Submit your manuscript at: http://papersubmission.scirp.org/

Or contact jsip@scirp.org 